T3, T4 were measured. Base on public health data and profiles, total number of newborns, gestational age, method of delivery, birth season and birth weight in whole population and for each of $\mathrm{CH}$ patients in addition of these data, their TSH measurements have been recorded.

Results During 5 years, 119701 neonates were screened and $\mathrm{CH}$ was confirmed in $10.8 \%$ (221) of the referral cases (prevalence $=$ 1:542). No significant statistical difference was seen between gender, birth season among $\mathrm{CH}$ patients and source population. Low birth weight ( $31 \%$ vs $4.9 \%$ - p value $<0.01)$, Postdate delivery $(1.4 \%$ vs $0.2 \%$ - p value $<0.01$ ) and macrosomia (were more prevalent in $\mathrm{CH}$. Odds of congenital hypothyroidism in a post-date delivery was 6.9 times of a term delivery. In low birth weight neonates odds of $\mathrm{CH}$ was 3.2 times of normal birth weight. Rate of NVD were higher in $\mathrm{CH}$ patients rather than source population (39.2\% vs $29.2 \%$ $\mathrm{p}$ value $=0.01)$

Conclusion LBW, postdate delivery and macrosomia are risk factors of congenital hypothyroidism.

\section{CAN WE COMPARE INDICATORS OF IODINE DEFICIENCY DISORDER IN NEONATE WITH SCHOOL- AGED CHILDREN?}

doi:10.1136/archdischild-2012-302724.1547

'S Dalili, ${ }^{2 Z}$ Mohtasham Amiry, 'SM Rezvany, ${ }^{1} \mathrm{~A}$ Dadashy, ${ }^{3} \mathrm{~A}$ Medghalchy, ${ }^{4} \mathrm{H}$ Dalili, 'A Mashaey, 'S Hosseiny, 'H Gholam Nezhad. 'Vice-Chancellor of Health; ${ }^{2}$ Social \& Preventive Medicine Department; ${ }^{3}$ Ophtalmology, Guilan University of Medical Sciences, Rasht; ${ }^{4}$ Neonatology Emam Khominy Hospital, Tehran University of Medical Sciences, Tehran, Iran

Objective To compare indicator of IDD in newborns with school age children.

Methods From 2006 to 2010, 119701 newborns were screened by measurement of blood TSH level by heel prick. The neonates who had blood TSH $>5 \mathrm{mu} / \mathrm{l}$ were recalled for more evaluation. In addition in same period of time, urine iodine were examined in 1200 school aged children and the severity of IDD were classified by WHO, UNICEF, I CCIDD criteria.

Results Between 2006-2010 a total of 9251, 23529, 27427, 29511, 29983 newborns were screened respectively and about \%1/7, \%1/4, $\% 2 / 1, \% 1 / 8, \% 1 / 9$ of screened neonates with TSH level equal or greater than $5 \mathrm{mu} / \mathrm{l}$ were recalled for more evaluation. Finally the incidence rate of Congenital hypothyroidism was 1/625. The result of urine iodine level in level in school aged children were $270 / 2$, 200/4, 200/1, 200, 200/2 mcg/1 respectively.

Conclusion If the WHO urine iodine criteria for school aged, and children WHO neonate TSH criteria were applied, Guilan province would be classified as having none IDD

\section{THE EFFECT OF QUALITY IMPROVEMENT INITIATIVES AS MEASURED BY NURSES' PERCEPTIONS IN A DEPARTMENT OF CHILDREN AND ADOLESCENTS}

doi:10.1136/archdischild-2012-302724.1548

A Solevåg, J Schrøder, I Madsen, AT Bjerke, B Nakstad. Dept. of Pediatrics, Akershus University Hospital, Lørenskog, Norway

Introduction In the context of a medium-sized Department of Pediatrics in Norway, a recent increase in the number of eligible patients including critically ill ones, has called for changes in the way clinical staff assesses and communicates around children in danger of clinical deterioration.

Aim We developed an educational plan for better recognition of and communication around critically ill children. The aim of the study was to investigate the methods nurses use in detecting clinical deterioration in a child, as well as their conceptions about communication prior to and one year after implementation of educational activities focused on the airways-breathing-circulation-disabilityexposure (ABCDE)-algorithm and of the identify-situationbackground-assessment-recommendation (ISBAR) communication tool (later referred to as "intervention").

Methodology The answers to two open-ended questions about nurses' pre-conceptions about assessment and communication, respectively from 66 nurses pre-intervention; and 48 nurses one year after intervention were analysed by content analysis.

Results Approximately half of the nurses reported to use the ABCDE-algorithm both prior to and after structured courses in this way of making assessments. Nurses often experience problems with communicating their concerns about deteriorating children to the physicians. Only $15 \%$ of nurses reported that this had improved after intervention. The fraction of nurses reporting concerns about communication was $29.5 \%$ pre- and $31.3 \%$ post-intervention.

Conclusion Despite efforts to make clinical staff assess and communicate more structured and similar, we could not prove an effect in our questionnaires. This may indicate that even harder and intensified actions including interprofessional ones over a longer time span are needed.

\section{SUN RELATED KNOWLEDGE AND ATTITUDES IN PRIMARY STUDENTS IN GREECE}

doi:10.1136/archdischild-2012-302724.1549

${ }^{1} \mathrm{M}$ Saridi, ${ }^{2} \mathrm{Kyriazis,}{ }^{3} \mathrm{M}$ Rekleiti, ${ }^{2 \mathrm{~K}}$ Bakalakou, ${ }^{4} \mathrm{~K}$ Lekka, ${ }^{5} \mathrm{~A}$ Kalokairinou, ${ }^{6} \mathrm{~K}$ Souliotis, ${ }^{7} \mathrm{~A}$ Kriembardis, ${ }^{5} \mathrm{~K}$ Birbas. ${ }^{1}$ Director of Nursing, General Hospital of Korinthos, Korinthos; ${ }^{2} 2 n d$ Internal Medicine Department, Asclepeion General Hospital Voula, Athens; ${ }^{3}$ General Hospital of Korinthos, Korinthos; ${ }^{4}$ Department of Educational Sciences and Early Childhood Education; ${ }^{5}$ Faculty of Nursing National and Kapodistrian University of Athens, Athens; ${ }^{6}$ Faculty of Social Sciences, University of Peloponnese, Peloponnese, ${ }^{7}$ Haematology and Transfusion Medicine Technological Institute Education of Athens, Athens, Greece

Background Childhood exposure to ultraviolet light increases the skin of skin cancer including melanoma.

Aim The aim of this study was to describe the sun-related knowledge and attitudes of primary schoolchildren in an urban area of Greece.

Methods A randomly selected sample of 2163 students (8-12 years old) from primary schools in an urban area of Greece was surveyed regarding their sun-related, knowledge and attitudes. SPSS 17.0 software was used for analysis with an alpha level set at $\mathrm{p} \leq 0.05$

Results $72 \%$ oh the children were living in coastal urban aereas and $15.8 \%$ didn't have Greek citizenship. General knowledge level of the students was satisfactory, $3.0( \pm 0.9)$, but only a small percentage $(27.1 \%)$ knew about efficient sun protection factor. Approximately $50 \%$ of children reported that they wore a hat and $72 \%$ used sunscreen to prevent themselves from getting sunburnt. Children who lived near the sea had a better behaviour to sun protection activities but older students had worse attitudes than elder ones and they had more sunburns too. Also, Greek children had better attitudes against other ethnicities. $31 \%$ of the pupils referred at least one sunburn at the last summer. In correlations, girls have more careful behaviour from boys and those children who do not used frequently sunscreen reported sunburn more often.

Conclusions Pupils of all ages need encouragement to protect their skin, to use sunscreens correctly and be aware of alternative sun-protection methods. Future health education needs to make pupils, parents and school staff aware sun exposure is not innocent.

1550 PHOTOTHERAPY AND DNA CHANGES IN FULL TERM NEONATES WITH HYPERBILIRUBINEMIA

doi:10.1136/archdischild-2012-302724.1550 